1. Harrison S. Patient safety: Cochlear implants. $\mathrm{Br}$ Dent J 2015; 219: 98.

2. Bashetty L, Nadig G, Kapoor S. Electrosurgery in aesthetic and restorative dentistry: A literature review and case reports. J Conserv Dent 2009; 12: 139-144.

3. Cochlear America Ltd. Available online at http:// www.cochlear.com/wps/wcm/connect/us/recipients/nucleus-5/nucleus-5-basics/mri-and-medical-considerations (accessed September 2015).

4. Med-El Ltd. Available online at http://www.medel. com/us/isi-cochlear-implant-systems/ (accessed September 2015).

5. Frampton S J, Ismail-Koch H, Mitchell T E. How safe is diathermy in patients with cochlear implants? Ann R Coll Surg Eng 2012; 94: 585-587.

6. Southern Cochlear Implant Programme. Available online at http://scip.co.nz/wp-content/ uploads/2014/11/BCIG-Guidelines-on-CochlearImplant-Safety.pdf (Accessed September 2015).

7. Shanavas M, Chatra L, Shenai P, Rao P K, Jagathish V, Kumar S P, Naduvakattu B. Transcutaneous electrical nerve stimulation therapy: An adjuvant pain controlling modality in TMD patients - A clinical study. Dent Res J 2014; 11: 676-679.

8. Cochlear America Ltd. Available online at http:// www.cochlear.com/wps/wcm/connect/in/home/ support/cochlear-implant-systems/nucleus-6/ common-questions/using-a-cochlear-implant (accessed September 2015).

9. Kim B G, Kim J W, Park J J, Kim S H, Kim H N, Choi $J$ Y. Adverse events and discomfort during magnetic resonance imaging in cochlear implant recipients. JAMA Otolaryngol Head Neck Surg 2015; 141: 45-52.

DOI: 10.1038/sj.bdj.2015.716

\section{DENTAL EDUCATION}

\section{Why introducing implementation science and stakeholder engagement belong in evidence-based dental education}

Sir, in previous publications, we described aspects of our approach to developing an evidence-based dental curriculum. ${ }^{1,2}$ In addition to teaching our dental students the fundamentals of epidemiology and observational study design, we are also providing exposure to our students on how to interpret and assess the quality of systematic reviews and metaanalyses, and introducing them to newer methodologies including the use of decision aids and patient-reported outcomes. It is important for dental students to be introduced to these emerging methods in other healthcare professions, such as medicine and nursing, as familiarity with these newer methods will prove beneficial in an era of increasing inter-professional collaboration.

Implementation science studies the use of strategies to adapt and use evidence-based interventions (EBIs) in targeted settings such as schools, workplaces, healthcare facilities and public health departments to sustain improvements to population health. ${ }^{3}$ Investments in basic and clinical research can be wasted if effective clinical or preventive models are not applied in practice. ${ }^{4}$ Evidence indicates that only about half of the available medical and public health innovations are currently used in practice but there are sufficient EBIs to reduce by more than 50\% the burden of cancer, chronic and infectious diseases in the United States. ${ }^{3}$ Implementation science does not necessarily use specific research methods but can include a broad range of traditional research approaches such as randomised trials, qualitative methods, systematic reviews and economic modelling. Most of the studies on implementation science in healthcare have focused on physicians and nurses but introducing dental students to the important aspects of implementation science, including stakeholder engagement, is crucial as the dental students of today are the dental researchers, practitioners and policymakers of tomorrow. To ensure that dental EBIs are implemented in the groups that need them most, including underserved populations, more involvement of other stakeholder groups besides scientists are needed and the opinions and expertise of policy and practice experts needs to be weighted more heavily. ${ }^{3}$

We increasingly talk about the need for ensuring dental students are competent in evidence-based methods and the importance of teaching proper methodological approaches but we should also be teaching students what it means to engage with stakeholders and encouraging them to also consider careers that involve helping to make policy.

\section{B. Laurence, Washington, USA}

1. Laurence B. Introduction to decision aids should be part of an evidence-based dental program. $N Y$ State Dent J 2014; 80: 9.

2. Laurence B. Integrating patient reported outcomes and other emerging methods into evidence-based dentistry. N Z Dent J 2014; 110: 130.

3. Lobb R, Colditz G. Implementation science and its application to population health. Annu Rev Public Health 2013; 34: 235-251.

4. Wensing M. Implementation science in healthcare: Introduction and perspective. Z Evid Fortbild Qual Gesundhwes 2015; 109: 97-102.

DOI: $10.1038 /$ sj.bdj.2015.717

\section{GRADUATES}

\section{Know the law}

Sir, I refer to the article 'Perception of studying dental law and ethics among postgraduate dental students in the UK' published in this Journal (BDJ 2015; 219:131-134).

I graduated, in 1993 having undertaken one of the first law and ethics in medicine courses in the UK at the University of Glasgow.

Unlike my experience of the BDS course, the law and ethics course required me to actually have to think about contentious issues and, at least try to, formulate an opinion about a broad range of 'medical', as opposed to specifically, 'dental' subjects mentioned in the article.

I firmly believe that a broad approach, including experience of such subjects, helps one to appreciate and better understand many areas of the subject such as patient autonomy, rights, consent etc.

A better understanding of the whole area must, of course, lead to better relationships between patient and clinician, but none of these issues, eg consent and confidentiality, is a 'stand alone' subject and, while not including the 'medical' topics may shorten a course, I consider that they should be included in order that the individual can develop a fuller awareness of the whole subject.

J. Pairman, Aberdeen

DOI: $10.1038 /$ sj.bdj.2015.718

\section{ANTIBIOTIC RESISTANCE}

\section{Clearer guidelines needed}

Sir, antibiotic resistance is a global problem and measures to research newer alternatives should be a priority as this poses a significant risk in the future. Each case should be considered carefully before prescribing antibiotics, and based on a correct diagnosis by appropriately trained staff. Some GPs and dentists may feel pressurised by patients who demand antibiotics as they feel it will make them better but clinicians should resist this and say no. There are new NICE guidelines on antibiotics.

It has been mooted that prescribers should be disciplined for over-prescribing which in my opinion is a ridiculous notion as this will be difficult to monitor and enforce. Both the GMC/RCN and GDC have clear standards expected from their registered members. I feel further threats to question clinical judgement could be detrimental and could lead to clinicians being over cautious and possibly doubt their own clinical diagnosis.

In my opinion, guidelines should consider a justification box within the FP10 prescription endorsement section. Recording a justification for giving antibiotics on the FP10 will help with audits on prescribing and could assist the pharmacist if there are issues with the prescription. Having a justification could also alert the pharmacist if they felt they needed to question the prescription, eg for a 'cold' or 'sinusitis' both self-limiting illnesses. It will require both clinicians and pharmacists to liaise closely together. Excellent teamwork and communication will be essential for both clinicians and pharmacists to ensure the best interests of the patients are met.

M. Parsons, Sheffield DOI: 10.1038/sj.bdj.2015.719 